Portland State University

PDXScholar

5-9-1996

\title{
Effects of Posttraining Maintenance Sessions on Aphasic Subjects' Verbal Labeling
}

Connie Allene Freed

Portland State University

Follow this and additional works at: https://pdxscholar.library.pdx.edu/open_access_etds

Part of the Speech and Rhetorical Studies Commons

Let us know how access to this document benefits you.

\section{Recommended Citation}

Freed, Connie Allene, "Effects of Posttraining Maintenance Sessions on Aphasic Subjects' Verbal Labeling" (1996). Dissertations and Theses. Paper 5202.

https://doi.org/10.15760/etd.7078

This Thesis is brought to you for free and open access. It has been accepted for inclusion in Dissertations and Theses by an authorized administrator of PDXScholar. Please contact us if we can make this document more accessible: pdxscholar@pdx.edu. 


\section{THESIS APPROVAL}

The abstract and thesis of Connie Allene Freed for the Master of Science in Speech Communication: Speech and Hearing Science were presented May 9, 1996, and accepted by the thesis committee and the department.

COMMITTEE APPROVALS:

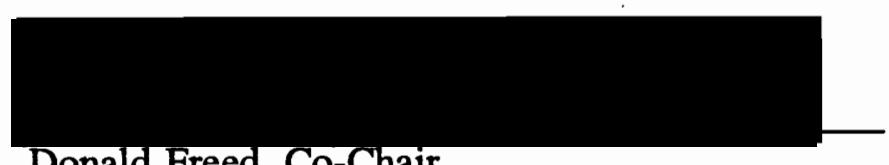

Donald Freed, Co-Chair

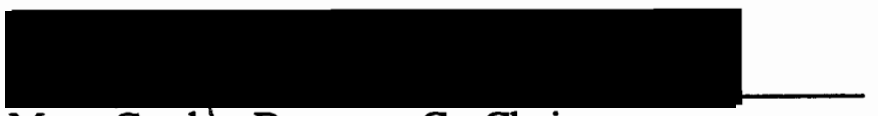

Mary Gorddn-Brannan, Co-Chair

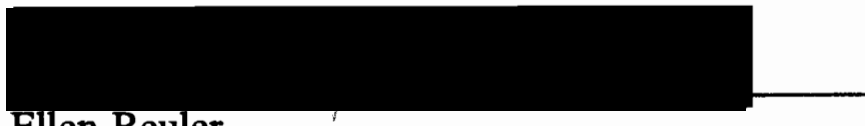

Ellen Reuler

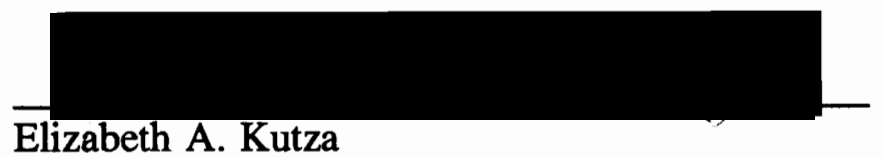

Representative of the Office of Graduate Studies

DEPARTMENT APPROVAL:

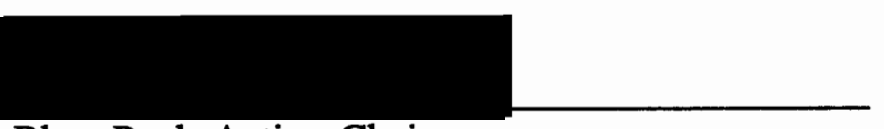

Rhea Paul, Acting Chair

Department of Speech Communication

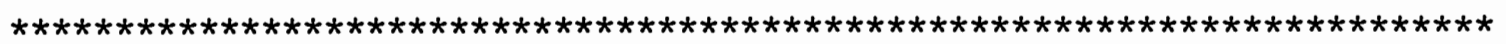

ACCEPTED FOR PORTLAND STATE UNIVERSITY BY THE LIBRARY

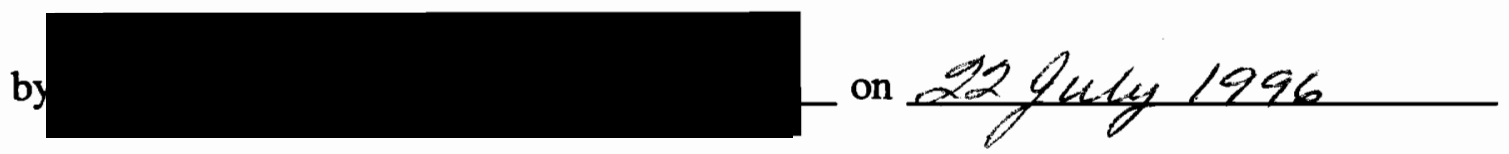




\begin{abstract}
An abstract of the thesis of Connie Allene Freed for the Master of Science in Speech Communication: Speech and Hearing Science presented May 9, 1996.
\end{abstract}

Title: Effects of Posttraining Maintenance Sessions on Aphasic Subjects' Verbal Labeling

For many years, treatment for word retrieval deficits has involved the use of various cueing techniques to help trigger retrieval of target words. Research has shown that accuracy for future retrieval of target words is best achieved by training subjects with semantically based cues. Personalized cues that are created by the subjects themselves to help remember a target word have been shown to be the most effective of the semantically based cues. However, even with the use of personalized cues, accuracy for naming tasks has been found to decrease once training is completed. Current research in memory indicates that, for normal subjects, techniques that facilitate future recall of information include testing, additional study, overlearning, and distributed practice.

This research examined the influence of posttraining maintenance sessions on the long term memory of subjects with aphasia. The goal was to compare the effect on naming accuracy for stimuli (a) presented in two additional training sessions (b) 
presented in one additional session, (c) not presented in any additional sessions. Additional sessions presented opportunities for testing, study, overlearning, and distributed practice for selected stimuli.

Three adult male subjects with moderate aphasia created their own cues to help remember 30 pictures of famous characters. During training sessions, these cues were presented to trigger name recall. Following the end of the 3-week training period, the 30 pictures were divided into groups of 10 cards called, A, B, and C. There were two additional training sessions for $\mathrm{A}$, one for $\mathrm{B}$, and none for $\mathrm{C}$.

A probe following the last session showed that for two of the subjects, the addition of posttraining maintenance sessions acted to enhance naming accuracy, and two sessions resulted in much higher accuracy than one session. This is consistent with research with normal subjects and suggests that short intermittent training sessions can help maintain naming accuracy with subjects with aphasia. 


\title{
EFFECTS OF POSTTRAINING MAINTENANCE \\ SESSIONS ON APHASIC SUBJECTS' \\ VERBAL LABELING
}

by

CONNIE ALLENE FREED

A thesis submitted in partial fulfillment of the requirements for the degree of

\author{
Portland State University \\ 1996
}




\section{ACKNOWLEDGEMENTS}

My most sincere thanks to Dr. Freed for guiding me through this fascinating and worthwhile project and giving me the opportunity to feel the thrill of being a successful researcher. Thank you for being helpful, generous with your time, and for always treating me as an equal. Your future students are, indeed, fortunate.

Thanks from my heart goes to my husband, Donald Hazelton, for being there for me every step of the way with boundless help, support, and love on what seemed an endless road. I hope that I can help him achieve his dreams now that he has helped me achieve mine. And final thanks to our daughter, Sasha, for providing the icing on our cake. 


\section{TABLE OF CONTENTS}

PAGE

CHAPTER

I INTRODUCTION AND STATEMENT OF PURPOSE $\ldots \ldots \ldots 1$

Introduction $\ldots \ldots \ldots \ldots \ldots \ldots \ldots \ldots \ldots \ldots \ldots$

Statement of Purpose $\ldots \ldots \ldots \ldots \ldots \ldots \ldots$

II REVIEW OF THE LITERATURE $\ldots \ldots \ldots \ldots \ldots \ldots$

Phonologically Based Cueing and Immediate Word Retrieval 6

Semantic Cueing and Maintenance of Word Retrieval Accuracy ................ 8

Personalized Cueing and Maintenance of Word

Retrieval Accuracy ............. 11

Increasing Retrieval of Information $\ldots \ldots \ldots \ldots \ldots 13$

The Act of Memory Retrieval . . . . . . . . . 14

Distributed Practice ................. 15

Overlearning $\ldots \ldots \ldots \ldots \ldots \ldots \ldots \ldots \ldots$

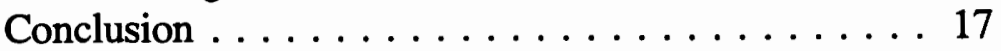

III METHODS $\ldots \ldots \ldots \ldots \ldots \ldots \ldots \ldots \ldots \ldots \ldots \ldots$

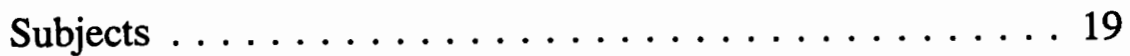

Experimental Stimuli $\ldots \ldots \ldots \ldots \ldots \ldots \ldots \ldots 21$

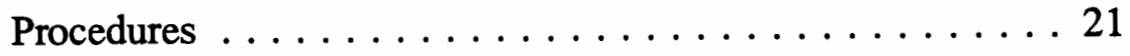

Preexperimental Probe ............... 21

Creation of Personalized Cues ........... 22

Training Trials $\ldots \ldots \ldots \ldots \ldots \ldots \ldots \ldots 22$ 
Posttraining Maintenance, Scheduling, and Stimuli . 24

Postmaintenance Probe .............. 24

Data Analysis . . . . . . . . . . . . 24

IV RESULTS AND DISCUSSION $\ldots \ldots \ldots \ldots \ldots \ldots \ldots$

Results .................... 25

Discussion .................... 29

V SUMMARY AND IMPLICATIONS $\ldots \ldots \ldots \ldots \ldots \ldots$

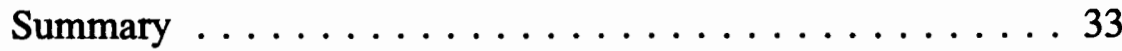

Implications $\ldots \ldots \ldots \ldots \ldots \ldots \ldots \ldots \ldots \ldots \ldots$

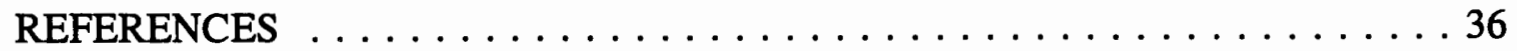

\section{APPENDICES}

A Informed Consent $\ldots \ldots \ldots \ldots \ldots \ldots \ldots \ldots \ldots \ldots \ldots \ldots$

B Information for Creation of Personalized Cues $\ldots \ldots \ldots \ldots 41$

C Terminology $\ldots \ldots \ldots \ldots \ldots \ldots \ldots \ldots \ldots \ldots \ldots$ 


\section{LIST OF TABLES}

PAGE

\section{TABLE}

1. List of Subject Characteristics $\ldots \ldots \ldots \ldots \ldots \ldots \ldots \ldots$ 


\section{LIST OF FIGURES}

PAGE

\section{FIGURE}

1. Sequence of Training Trials and Probes $\ldots \ldots \ldots \ldots \ldots 23$

2. Mean Percentage of Correct Responses During the

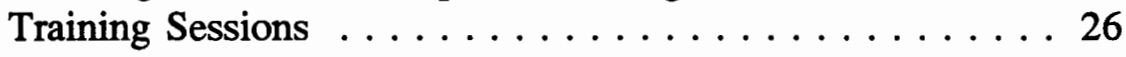

3. Mean Percentage of Correct Responses During the Maintenance Sessions . . . . . . . . . . . 27

4. Mean Percentage of Correct Responses During the Postmaintenance Probe $\ldots \ldots \ldots \ldots \ldots \ldots 28$ 


\title{
CHAPTER I
}

\section{INTRODUCTION AND STATEMENT OF STATEMENT}

\author{
Introduction
}

Word retrieval problems are almost universal among patients who are aphasic (Goodglass, 1993). This difficulty is extremely frustrating and stressful for the many adults with aphasia who often can not remember the names of common objects used in daily living. In order to address this issue, confrontation naming exercises in which a client is asked to name a single object or a picture of an object are a common part of treatment. To help trigger word retrieval, speech/language pathologists have, for many years, presented cues to their clients as part of their treatment program.

Cues used in confrontation naming tasks are usually phonologically based or semantically based. Examples of phonologically based cues include repetition of the target word, making a judgment of whether or not a word rhymes with another, and saying the sound of the first phoneme of the target word. Semantic cueing techniques rely on the client analyzing the meaning of a word. Functional descriptions and sentence completion tasks are examples of two common semantic cueing techniques used to enhance word retrieval.

As with all aspects of aphasia treatment, the goal is to use techniques in treatment that will improve the communication ability of the client, not only during 
the clinical session itself, but in future communication situations as well. A treatment technique usually can only be considered effective if it has a long-lasting, positive influence on future communicative ability. The term "maintenance" is often used to refer to the preservation over time of improvements made during treatment sessions (Howard, Patterson, Franklin, Orchard-Lisle, \& Morton, 1985a). In the case of word retrieval, the maintenance of therapeutic effect would be demonstrated by the continuation of a significantly higher accuracy in naming of trained items long after formal treatment has ended.

Early research concerning the efficacy of cueing for visual naming tasks was only concerned with which cueing techniques best elicited immediate word recall (Li \& Williams, 1989; Love \& Webb, 1977; Pease \& Goodglass, 1978). Few, if any, studies focused on maintenance of naming ability beyond that of the immediate response.

While aphasia research for word retrieval focused on the immediate effect of cueing, research that examined learning with normal subjects was finding that memory tasks focusing on word meaning or semantics can lead to increased word retrieval over time compared to tasks using phonologically based procedures. In the 1970s, a team of psychologists at the University of Toronto found, through a series of experiments, that normal subjects who had to perform a semantic analysis of words exhibited greater accuracy for word retrieval during tests of recall (Lockhart, Craik, \& Jacoby, 1976). Based on their research, Craik and Lockhart (1972) developed what they called a "levels of processing model" for the encoding, storage, and retrieval of 
target stimuli. In this model, shallow processing by an individual is comprised of simple phonological analysis of the stimuli such as deciding if one word rhymes with another. In contrast, deep processing results from thinking about a word's meaning such as deciding whether two words are synonyms. Deeper processing results in an increased ability to retrieve target information over time (Craik \& Lockhart, 1972).

Although this body of research in normal memory and learning pointed to an increase in memory enhancement through the use of semantic encoding, it was a decade later that aphasia researchers began to investigate whether semantic or phonemic cueing resulted in higher maintenance of accuracy in confrontation naming tasks. In 1983, Patterson, Purell, and Morton examined the long-term effectiveness of the first phoneme cue, a cueing procedure commonly used in aphasia treatment. Their study showed that presentation of the first phoneme cue resulted in increased naming at the moment of cue presentation. However, when the same target words were presented only 30 minutes later without a cue, successful word recall returned to baseline levels. As a result of this finding, research rapidly shifted to ascertain if any of the other cueing techniques currently used in aphasia treatment also resulted in maintenance of naming accuracy over time (Howard et al., 1985a; 1985b).

Recent research has shown that a self-cue (hereafter described as a personalized cue), a semantic cue made up by the aphasic subjects themselves to help remember a word, produced the highest levels of labeling accuracy after a one-week period (Marshall, Neuberger, \& Phillips, 1992). However, even with the personalized 
cues, word retrieval accuracy decreases once treatment 15 discontinued (Freed, Marshall, \& Nippold, 1995).

While there are few leads to follow in aphasia research that might lead to a solution to the maintenance problem, research in retrieval of information in normal subjects does suggest at least four possibilities. First, it has been known for years that the act of retrieving information is a powerful facilitator to retrieving the same information in the future (Bjork \& Bjork, 1992). Second, study trials interspersed with tests have been shown to increase accuracy for information retrieval (Allen, Mahler, \& Estes, 1969). Third, distributive practice or spaced exposure to stimuli has been shown to be much more effective than massed study for accuracy of future retrieval of information (Bjork \& Bjork, 1992). Fourth, overlearning has been shown to increase probability of recall with normal subjects (Krueger, 1929).

Subjects who are aphasic may be able to maintain their accuracy to name target stimuli through the use of one technique or a combination of these techniques that have been effective with normal subjects. Therefore, it is possible, that through the use of spaced maintenance training sessions, the naming accuracy for trained stimuli can be enhanced in subjects who are aphasic. These maintenance sessions would be additional brief sessions following the end of the formal training period in which opportunities for additional distributive study, testing, and recall of stimuli would be created. 


\section{Statement of Purpose}

In this research, the influence of posttraining maintenance sessions on long-term memory of aphasic subjects for visual naming tasks was examined. The following questions were addressed:

1. Is naming accuracy for visual stimuli increased in subjects trained in the use of personalized cues by the presence of posttraining maintenance sessions?

2. If there is an increase in accuracy with the presence of posttraining maintenance sessions, do two posttraining sessions result in a higher number of accurate responses than one session?

The corresponding null hypotheses tested were:

1. Naming accuracy will not be increased by the presence of posttraining maintenance sessions.

2. Two posttraining sessions do not result in a higher number of accurate responses than one session. 


\section{CHAPTER II}

\section{REVIEW OF THE LITERATURE}

The focus of this chapter is on research that involves the use of various cues used in aphasia treatment to enhance word retrieval. Phonologically and semantically based cues will be reviewed. Further discussion will be presented pertaining to one specific semantically based cueing technique: the personalized cue. The facilitation of retrieval of information in normal subjects will be examined and theoretically applied to a study designed for subjects who are aphasic to help them maintain their word retrieval accuracy following the end of formal treatment training.

\section{Phonologically Based Cueing and Immediate Word Retrieval}

Early cueing studies did not delve into whether or not cueing resulted in long term gains in word retrieval. In an early study comparing the age of acquisition of words in children to word retrieval problems in aphasic adults, Rochford and Williams (1962) used four different types of cues. They found that word association, rhyming, and spelling the word were equally effective cues for immediate recall for their adult subjects with aphasia. Describing an object's use was less than $50 \%$ as effective as a cue when compared to any of the other three.

Love and Webb (1977) systematically studied the efficacy of three different cues in a confrontational naming task of common items. When 20 subjects with 
aphasia were asked to name 30 objects depicted in black and white line drawings, cues were systematically presented to assist in word retrieval when a subject failed to name a picture. Of the three cues presented, the presentation of the first syllable was twice as effective for immediate word recall as sentence completion or reading the printed name, which did not differ significantly from each other.

In another study involving a confrontational naming task, Pease and Goodglass (1978) compared the efficacy of six different cues: (a) initial phoneme, (b) superordinate semantic class of target word, (c) location/environmental context, (d) rhyme, (e) function of the object, and (f) open ended sentence completion. The most effective cue was the first phoneme, with sentence completion being next in effectiveness. The other cue techniques did not vary significantly from each other, but all cues had some beneficial effect on immediate naming.

Li and Williams (1989) performed a similar study and compared the immediate effects of phonemic and semantic cues. Subjects with aphasia were prompted in confrontational naming tasks with either a first phoneme or a semantic cue that was either a description of object function, a description of object action, or a functional context for the object. The first phoneme cue was the most effective in eliciting immediate word retrieval. Although these studies clearly demonstrated that some cues are more effective than others in immediately eliciting target words, research on aphasia had not addressed the issue of long-term maintenance of word retrieval treatment. 
Semantic Cueing and Maintenance of Word Retrieval Accuracy

An early study to examine the long-term maintenance of word retrieval following treatment was conducted in 1981 in a single case study by Thompson and Kearns. They did not compare the efficacy of various techniques, but examined the combined effect of various cues presented in a hierarchy. The order of cues to be presented to the aphasic subject when a word could not be recalled was (a) sentence completion, (b) sentence completion plus a phonetic cue, and (c) sentence completion cue plus a verbal model. Posttraining accuracy for recall of stimuli was tracked for several months and was found to remain significantly higher than naming accuracy for the same items prior to training.

In 1983, Patterson et al. also looked beyond the immediate benefits of the first phoneme cueing technique and examined the effects of cueing on subsequent recall attempts of subjects with aphasia. They found that first phoneme cues resulted in high levels of accurate, immediate retrieval of the target words. However, following a 30 minute interval, accuracy of naming returned to baseline when the same words were targeted without the phonemic cues. This finding suggested that the effects of first phoneme cueing on naming accuracy for subjects with aphasia was of such a short duration that carryover of treatment effects to situations outside of the clinical setting was unlikely.

Howard et al. (1985a) compared different cueing techniques to determine which resulted in the most accurate naming over time. They drew a clear distinction between cues that were prompting in nature and those that were facilitating. 
Prompting was defined as the "application of a single technique which is intended to ameliorate naming difficulty at the time a patient Is trying unsuccessfully to find a word " (p. 50). Facilitation was defined as "application of a single technique with a view to assessing its specific effects at some later time" (p. 50).

Using a series of four experiments, Howard et al. (1985a) evaluated the maintenance of naming accuracy after treatments that involved either semantically or phonologically based tasks. The first experiment compared two auditory word-to-picture matching treatment tasks. In the first, subjects were to point and name a specific visual stimuli when presented a card with four pictures. In the second, subjects simply pointed to the correct picture but remained silent. These tasks were considered to be semantically based. Both tasks resulted in higher naming accuracy 20 minutes later when compared to control items.

In their second experiment, the task remained the same, but the pictures were all members of the same semantic category. Significantly higher naming accuracy was evident 20 minutes posttreatment and after 24 hours as well.

Subjects were given a pretest in the third experiment. Pictures not successfully named on the pretest were used for training under two conditions. In the first, subjects matched written words to a choice of four pictures. In the second, subjects did not see the pictures but instead made semantic judgments about the pictures missed on the pretest. Both tasks resulted in the higher naming accuracy for both conditions 20 minutes after treatment. Two weeks later, however, testing indicated that any facilitating benefits of the training had fallen below significant levels. 
In the final experiment, the facilitating benefits of three phonologically based techniques were tested. A comparison was made of naming recall for items trained by (a) repetition, (b) rhyme judgment, and (c) rhyme cue. Naming accuracy was high for immediate recall, but the facilitating effect was no longer evident 30 minutes later for any of the three techniques when compared to controls. As in the Patterson et al. study (1983), the phonologically-based cues acted as prompts that enhanced immediate recall, but had no facilitating value for future recall attempts.

In another study, Howard et al. (1985b) compared the effects of phonologically and semantically based techniques over a longer period following treatment. Subjects were trained to name items with either a combination of semantically based techniques (word-to-picture naming, visual word-to-picture naming, and semantic judgments) or with a combination of phonologically based techniques (repetition, first phoneme cue, and rhyme judgments). Both procedures increased immediate recall for naming and for recall one week after the end of treatment. However, no maintenance of effect for either type of treatment was evident for either condition 5 weeks following treatment. The authors speculated that subjects had not received a critical amount of treatment and, therefore, the effects were not long-term.

Marshall, Pound, White-Thompson, and Pring (1990) investigated maintenance of word recall following training with semantically-based techniques involving written word-to-picture pointing tasks. Three single subject studies and one group study involving 3 subjects were conducted. Naming accuracy increased significantly in two 
of the three single subject studies. The group study not only showed an immediate increase in naming accuracy, but this increase remained significantly higher one month post-treatment.

In the longest spanning study of word retrieval maintenance, Pring, White-Thompson, Pound, Marshall, and Davis (1990) were able to do posttreatment testing of 6 of the 7 original members from the Marshall et al. (1990) study one year later. While decline in accuracy had occurred, a significantly higher level of naming accuracy was still present for treated items over untreated control items.

This success of the semantic cue and semantic training techniques is not surprising if viewed in light of Lockhart and Craik's level of processing model (Lockhart et al., 1976). Their research pointed to the superiority of semantic processing for memory retention. According to their model of learning and memory, semantic analysis leaves deeper traces in memory. During future retrieval operations, target word recall is easier due to these deeper traces, and this is manifested by higher and more durable accuracy of retrieval.

\section{Personalized Cueing and Maintenance of Word Retrieval Accuracy}

Research continued to focus on the best cue to facilitate long-term word retrieval. Marshall et al. (1992) compared the maintenance of labeling accuracy following training that simulated eight different treatment techniques in a word-to-symbol labeling task. Abstract novel symbols were used as the experimental visual stimuli to rule out the influence of prior learning on word retrieval 
performance. Seven of the simulated treatment techniques were ones that are commonly used in aphasia treatment activities: (a) auditory word-to-symbol naming, (b) visual word-to-symbol naming, (c) auditory plus visual word-to-picture matching, (d) non-rehearsal auditory word-to-symbol matching, (e) repetition, (f) determinate sentence completion, and $(\mathrm{g})$ indeterminate sentence completion. The eighth condition was personalized cueing, a semantically based training technique. Here, subjects made up their own verbal cues to help them associate the target words paired with the symbols. These cues were recorded and used in subsequent training trials. One week posttreatment, the experimental stimuli trained via personalized cues showed significantly higher levels of labeling accuracy compared to the items trained in the other seven techniques.

Marshall, Freed, and Phillips (1994) continued research with maintenance of word recall using a similar novel symbol naming task. This study compared the effects of first phoneme cues and personalized cues on the labeling of novel symbols by subjects with aphasia. The results showed that during training trials, significant increases in naming accuracy resulted from both techniques. However, probes at midtraining, posttraining, and 24 hours posttraining showed labeling accuracy was significantly higher for the personalized cueing condition than for the phonemic cue condition.

While the personalized cue shows promise as a facilitating technique, maintenance of long-term memory for symbol-to-word memorization tasks has been shown to decrease over time. Freed et al. (1995) found that the mean percentage of 
correct answers 72 hours after completion of self-cueing training was $92 \%$. However, after 30 days, the mean percentage of correct answers had dropped to $50 \%$. While accuracy for word recall was still significantly improved over baseline ability, the authors concluded that further research is needed to find an effective method of maintaining accuracy for naming trained stimuli over time.

\section{Increasing Retrieval of Information}

Researchers have often debated the reason that subjects with aphasia actually experience word retrieval difficulty, whether the disruption is occurring at the level of encoding, at the storage level, or at the retrieval level itself Hillis, 1989; Le Dorze, 1989; Wiegel-Crump, \& Koenigsknect, 1973) . A recent study (Beeson, Bayles, Rubens, \& Kaszniak, 1993) found that the breakdown did not appear to be at the encoding and storage level, but rather at the level of retrieval, and that semantic cueing resulted in equally high levels of retrieval for subjects who are normal and subjects with aphasia.

With research indicating that subjects with aphasia can accurately encode and store information (Beeson et al., 1993) and that semantic cueing is an effective facilitator to help with word retrieval (Marshall et al., 1992; Marshall et al., 1994), the question then remains what additional tasks can be done to maintain the accuracy of word retrieval over time. Clients with aphasia can not stay in treatment indefinitely receiving training to help facilitate recall of specific words. However, research in 
facilitation of long-term memory involving normal subjects suggests effective and efficient ways to maintain high word retrieval accuracy for subjects with aphasia.

\section{The Act of Memory Retrieval}

According to Bjork and Bjork (1992) one simple and powerful facilitation technique that greatly increases future recall is the act of retrieving or remembering a piece of information. They provided this explanation of the effect on memory of retrieving or remembering an item of information:

In terms of its positive consequences, the act of retrieval is itself a potent learning event. As an overall generalization, the act of retrieving an item of information is considerably more potent in terms of facilitating its subsequent successful recall than is an additional study trial on that item. (p. 37)

Retrieval opportunities in the form of tests have also been shown to facilitate word retrieval. According to Cooper and Monk (1976), "A test trial consolidates the learned material in some way leading to resistance to forgetting in delayed recall and a stereotyping of the responses" (p. 136). Allen et al. (1969) found a combination of both testing and study was the best method to facilitate recall of information with normal test subjects. In their study, subjects were presented with 27 three-letter nouns that were paired with 27 two-digit numbers to memorize. A comparison was made between the accuracy of (a) recall of items trained with study trials alone and (b) items trained with an identical number of study trials plus one test to recall studied items presented immediately following the last study trial. The addition of the one test resulted in an increased accuracy of almost $50 \%$ when compared to items receiving the same amount of study but without the test. In a similar study, Hogan 
and Kintsch (1971) found that retrieval was higher for words that had been presented in the form of one study trial followed by three recall tests than for words that had been presented in four study trials.

More recently, Carrier and Pashler (1992) designed a study to see if recall tests and the act of retrieval itself facilitate future retrieval or whether recall testing simply supplies an additional presentation of target items and in doing so, simply acts as another study trial. Normal subjects were presented with pairs of words, one to act as the test stimulus and the other as the target word for recall. Under the pure study trial condition, both stimulus and target words were presented simultaneously for 10 seconds to study. In a second condition called the test trial/study trial, the stimulus word was presented alone for 5 seconds after which the target word it was paired with was presented along side it for an additional study time of 5 seconds. More stimulus presentation time was available for the pure study group pairs. The test trial/study trial pairs were not given additional study time for stimulus and target pairs. However, additional retrieval opportunities existed because the stimulus was presented without the target. The results showed higher recall for word pairs in the test trial/study trial condition than in the pure study condition. The authors maintained that the results support the validity of retrieval as a separate and effective facilitator for recall, not simply an additional opportunity for study.

\section{Distributed Practice}

Another technique that enhances memory Is that of distributed practice or spaced repetitions of study trials. Spaced repetitions of information result in a slower 
deterioration of retrieval ability than does massed repetition of the same information (Bjork \& Bjork, 1992). Furthermore, an expanding interval between test trials is superior to short intervals and results in higher retrieval ability. In a study designed to test optimum test spacing for name recall (Landauer \& Bjork, 1978), normal subjects were given names to memorize followed by recall tests presented at varying intervals. The three different patterns for the intervals between six recall tests were (a) uniform intervals, (b) expanding intervals in which the time between tests grew gradually longer, and (c) contracting intervals with the time between tests grew gradually shorter. When a final recall test for all conditions was performed, the expanding condition was significantly better than the uniform and contracting condition.

Lockhart et al. (1976) interpreted superiority of distributed testing for recall in terms of their level of processing model. According to their model, when an item is retrieved from memory, a "trace" is left of that retrieval activity that helps in future retrieval of the same information. As mentioned previously, semantic processing results in deeper, more durable traces. However, according to their model, very short intervals between retrieval result in short cuts in the retrieval process that do not leave as durable a trace as would retrieving the same information after a longer interval.

Bjork and Bjork (1992) maintained that while retrieval is the strongest facilitator for future information retrieval, repeated study over time acts to increase the storage strength of the information and reduces the loss of retrieval strength for that information. 


\section{Overlearning}

Overlearning, or studying items successfully retrieved on recall tests, has also been shown to increase probability of recall with normal subjects. In 1929, Krueger conducted a study in which normal subjects were given study trials of a word list until they achieved $100 \%$ accuracy. Subjects who were given additional study trials after having achieved $100 \%$ accuracy were found to exhibit higher maintenance for recall after a 28-day interval than subjects who stopped study trials when they reached $100 \%$ accuracy.

\section{Conclusion}

The personalized cue procedure has been shown to result in relatively long-lasting maintenance of recall word accuracy when compared to other techniques (Marshall et al., 1992). However, even when personalized cueing is used as a training procedure, a decline in naming accuracy begins shortly after the withdrawal of training (Freed et al., 1995). While application of techniques that have only been used with normal subjects may be problematic, it is possible that word retrieval accuracy for subjects with aphasia could be maintained at higher levels if subjects were presented with additional short study trials and tests for trained stimuli after the period of formal training has ended.

In this research project, subjects were exposed to additional study trials plus additional test trials offered at spaced intervals using personalized cues. As has been established, study trials and test trials serve to strengthen retrieval strength, and distribution of study is superior to massed study. It is possible that some items could 
be over learned which could also facilitate word retrieval. The personal cue which is semantically based may also provide a deep level of processing of the stimuli. If it is found that additional posttraining maintenance sessions enhance the word retrieval accuracy of the subjects, the results could lead to important clinical applications. The following methods were based on these assumptions. 


\section{CHAPTER III}

\section{METHODS}

In this research, the effect of posttrainlng maintenance sessions on the long-term memory of naming visual stimuli by subjects trained in the use of personalized cues were examined. This study was a single subject multiple-schedule design.

\section{Subjects}

Subjects for this study were 3 adult males between the ages of 50 and 75 years old. A consent form was signed by all subjects (see Appendix A). They were all right-handed and had experienced a single left hemisphere cerebrovascular accident. All three had been diagnosed as aphasic based on results of the Western Aphasia Battery (Kertesz, 1982), Boston Diagnostic Aphasia Examination (Goodglass \& Kaplan, 1983), or Minnesota Test for Differential Diagnosis of Aphasia (Schuell, 1972). The aphasia severity for all subjects was moderate, based on scores of the Porch Index of Communicative Ability (PICA; Porch, 1981). The range of their PICA overall percentile scores was between 61 and 75 (see Table 1). Subjects were informally screened for any visual and auditory deficits that would interfere with their ability to respond to the experimental stimuli. 
TABLE 1

LIST OF SUBJECT CHARACTERISTICS

\begin{tabular}{||l|c|c|c||}
\hline & $\begin{array}{c}\text { Subject } \\
\text { EH }\end{array}$ & $\begin{array}{c}\text { Subject } \\
\text { GM }\end{array}$ & $\begin{array}{c}\text { Subject } \\
\text { DS }\end{array}$ \\
\hline Date of Birth & $04 / 14 / 39$ & $06 / 23 / 25$ & $07 / 26 / 29$ \\
\hline Months Post-Onset & 11 & 146 & 99 \\
\hline Aphasia Type & Nonfluent & Nonfluent & Nonfluent \\
\hline Overall percentile on PICA & 75 & 61 & 72 \\
\hline Verbal percentile on PICA & 82 & 61 & 64 \\
\hline Western Aphasia Battery Aphasia Quotient & 74 & 76 & 85 \\
\hline Boston Naming Test & 52 & 46 & 55 \\
\hline Ravens Progressive Matrices & 25 & 26 & 34 \\
\hline Pyramid and Palm Trees 3 Picture Test & 51 & 48 & 46 \\
\hline
\end{tabular}

All 3 subjects were diagnosed as having nonfluent aphasia. Subject DS was 66 years old and the least physically impaired of the 3 subjects. Word retrieval difficulties made his conversation somewhat halting, although he could readily speak on a variety of topics. He exhibited mild spastic dysarthria, but his speech was $100 \%$ intelligible.

Subject EH was 57 years old and the youngest of the subjects. He had severe apraxia and would often require multiple attempts to produce a word. His conversational speech was very halting due to a combination of aphasic word retrieval problems and apraxia. Often he would perseverate on a word previously spoken. 
When he was able to retrieve and formulate his words correctly, subject EH's speech was $100 \%$ intelligible.

At 70 years old, subject GM was the oldest of the 3 subjects and the most physically disabled. He was severely apraxic and had moderate flaccid dysarthria. His conversational speech was halting with reduced volume and was about $80 \%$ intelligible to an unfamiliar listener. Although he had difficulty speaking, subject GM was a lively and determined communicator.

\section{Experimental Stimuli}

Thirty-five different black and white pictures of famous historical figures or fictional characters were used as the experimental visual stimuli. Characters and figures selected had a high likelihood of name familiarity, but low likelihood of facial recognition (see Appendix B).

\section{Procedures}

\section{Preexperimental Probe}

A preexperimental probe before training measured each subject's ability to name each of the 35 pictures as they were presented one at a time. In the event that a subject guessed the name paired with a picture, this picture was not used. Subjects GM and EH were apraxic, and therefore, if they could not intelligibly pronounce a target name, that stimuli was not used in their training. Each subject had a zero baseline for all 35 pictures, and 30 pictures were chosen for each subject. 


\section{Creation of Personalized Cues}

After baseline was established, the pictures were presented to the subjects one at a time (see Figure 1 for training schedule). The subjects were asked to make up their own personalized cues to help them remember the names paired with the pictures. The researcher read a short paragraph about each famous person or character to the subject (see Appendix B). The researcher told the subjects to make up their own cues consisting of words or phrases and to try to keep the cue no longer than five words. Only a few of the cues were longer than five words. Examples and assistance were provided if needed, and the personalized cues created by each subject for each picture were recorded.

Cues created by the subjects for the same picture were often very similar and occasionally identical. For example, the three cues created for Romeo were, fell in love with Juliet, fell in love with Juliet, and loved Juliet. For other stimuli, there was variety among the cues. For example, the three cues for Scrooge were, bah, humbug, Christmas miser, and vested by Christmas ghosts.

\section{Training Trials}

During training sessions, the pictures were presented one at a time along with the personal cue, and the subjects were asked to recall the name of the person. If they did not remember, they were told the correct name. The pictures were presented twice during a training session. There were three training sessions per week for a period of 3 weeks. 


\section{Week One}

Pretraining Probe and Creation of Personalized Cues

\section{Week Two}

Three Training Sessions

\section{Week Three}

Three Training Sessions

\section{Week Four}

Three Training Sessions

Posttraining Maintenance Sessions - One Session Per Week
A Cards
B Cards
C Cards

Week Five $\quad$ X

Week Six

$\mathrm{X}$

Week Seven $\quad$ X

Week Eight

Postmaintenance Probe

FIGURE 1

SEQUENCE of Training TRIals AND PRoBes 
Posttraining Maintenance, Scheduling, and Stimuli

Immediately following the final training session, the 30 pictures were randomly divided into three groups of 10 pictures called A, B, and C. Each subject returned for two maintenance sessions that only used the A cards for training. Procedures for the maintenance sessions were identical to the training sessions. The first session was 1 week following the last training session and the second session 3 weeks after the last training session. With two sessions (A cards), opportunities existed for additional test trials, distributed practice, overlearning, and additional study. With a single additional training session (B cards), the same opportunities existed, but to a lesser degree than with the two maintenance session condition. The $\mathrm{C}$ cards were not used in any additional sessions, and therefore there were no additional opportunities for facilitation of future word recall.

\section{Postmaintenance Probe}

Four weeks after the last training session, a postmaintenance probe was performed. The 30 pictures were randomly shuffled and then presented to each subject. Subjects were asked to identify each of the pictures. No cues or answers were provided.

\section{Data Analysis}

A tally was made of the correct posttest responses of each subject for the three groups of cards, and a graph was made of each total for the purpose of visual analysis. 


\title{
CHAPTER IV
}

\section{RESULTS AND DISCUSSION}

\author{
Results
}

In this study, the following two questions were addressed:

1. Is naming accuracy for visual stimuli increased in subjects trained in the use of personalized cues by the presence of posttraining maintenance sessions?

2. If there is an increase in accuracy with the presence of posttraining maintenance sessions, do two posttraining sessions result in a higher number of accurate responses than one session?

For 2 of the 3 subjects, an increase in naming accuracy resulted with the presence of posttraining maintenance sessions. For these same 2 subjects, two posttraining maintenance sessions resulted in a higher number of accurate responses than one session.

Figure 2 shows the mean percentage of correct responses for each subject during the nine training sessions. Mean percentage of correct responses during the three posttraining maintenance sessions are shown in Figure 3. The percentage of correct responses during the posttest is grouped according to the number of posttraining maintenance sessions and shown in Figure 4. 


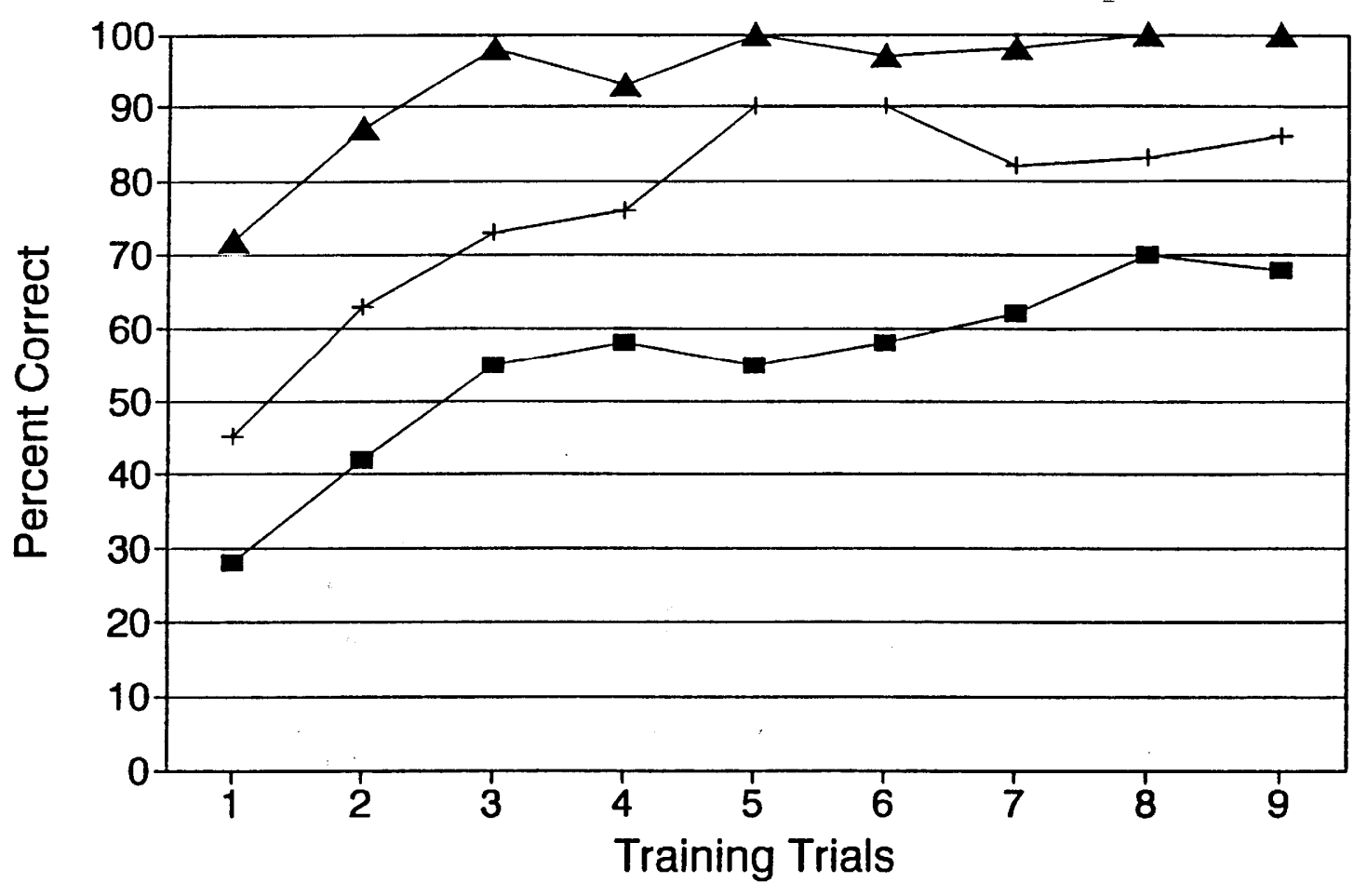

$\rightarrow-$ Subject DS ־ Subject EH $\neg-$ Subject GM

FIGURE 2

MeAN PERCENTAGe OF CORRECT Responses DURING THE

TRAINING SESSIONS 


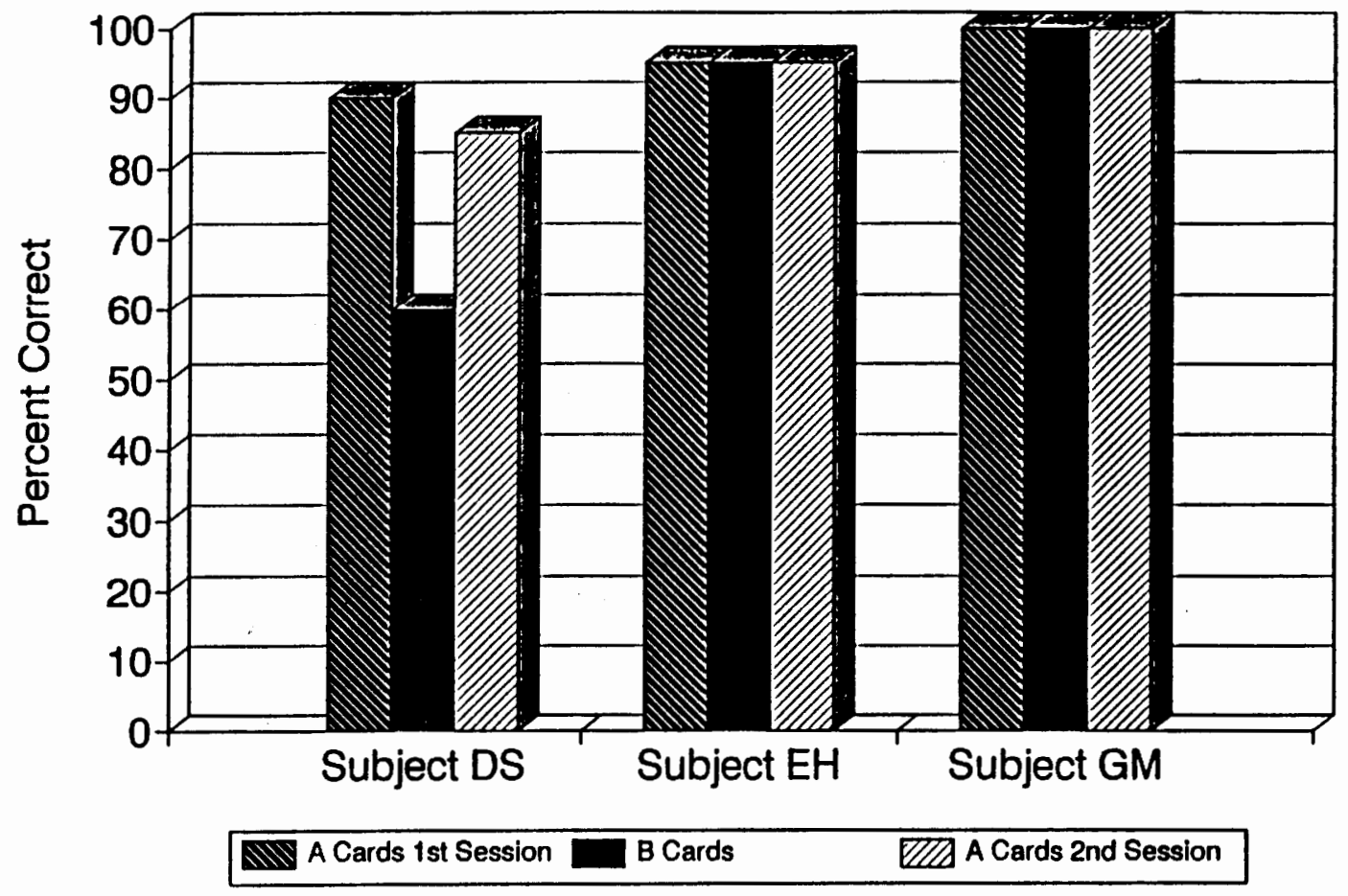

FIGURE 3

Mean Percentage of Correct Responses DuRing the MAINTENANCE SESSIONS 


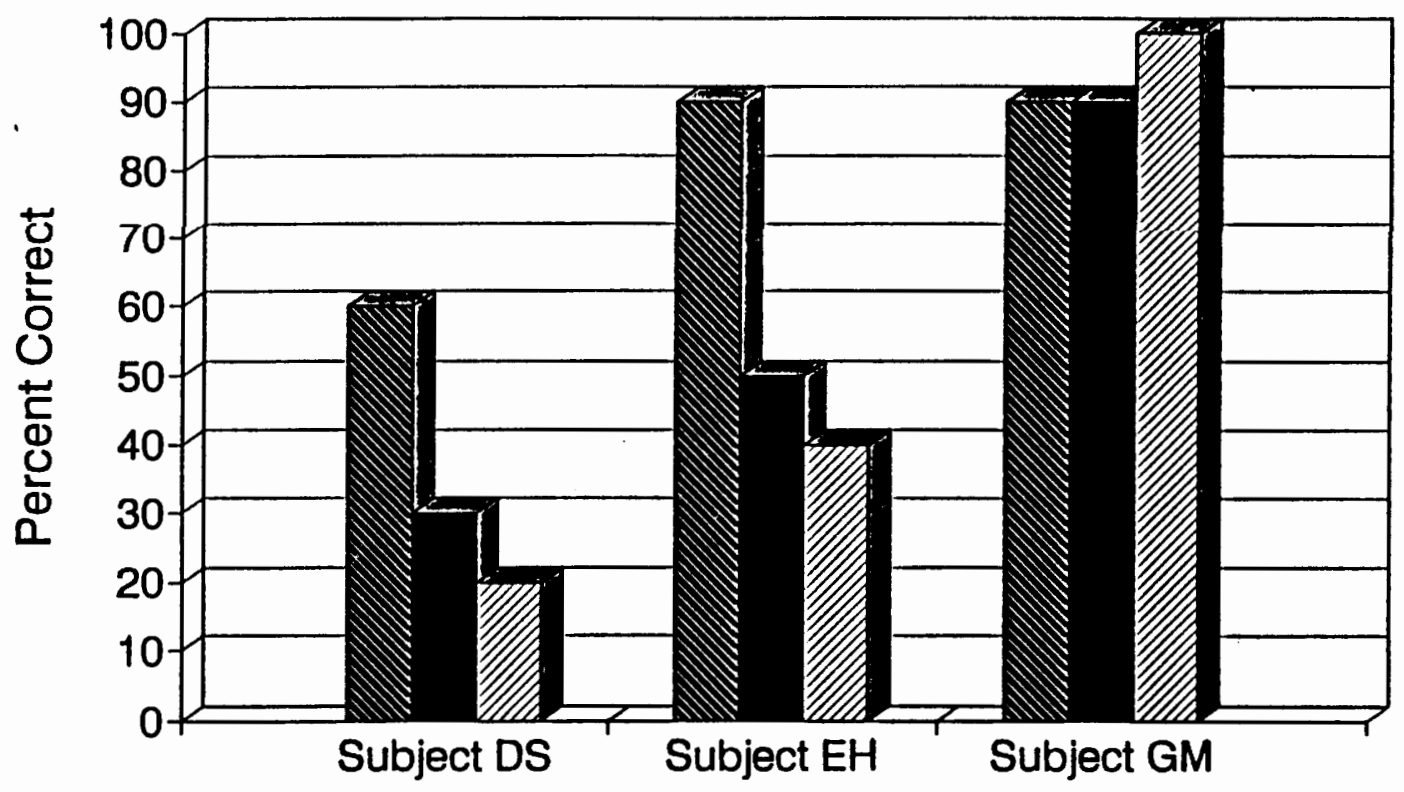

\section{$\mathbb{1 1}$ Card Set A $\square$ Card Set B WTIA Card Set C}

FIGURE 4

MEAN PERCENTAGE OF CORRECT RESPONSES DURING THE POSTMAINTENANCE PROBE 
Subject DS correctly identified a mean of $68 \%$ of the stimuli during his last training session. During the posttest 4 weeks later, he correctly identified $60 \%$ of the stimuli with which he received two posttraining sessions (card set $\mathrm{A}$ ), $30 \%$ with one session (card set B), and $20 \%$ with no additional sessions (card set C).

Subject EH correctly identified a mean of $86 \%$ of the stimuli during his last training session. During the posttest 4 weeks later, he correctly identified $90 \%$ of the stimuli with which he received two posttraining sessions, $50 \%$ with one session, and $40 \%$ with no additional sessions.

Subject GM correctly identified a mean of $100 \%$ of the stimuli during his last training session. He correctly identify $90 \%$ of the stimuli with which he received two posttraining sessions, $90 \%$ with one session, and $100 \%$ with no additional sessions.

\section{Discussion}

The results suggest that multiple intermittent posttraining maintenance sessions can enhance aphasic subjects' naming accuracy over time. The study showed that for 2 of the 3 subjects, two additional posttraining maintenance sessions resulted in much more accurate naming on the 4-week probe compared to one session or no sessions. These spaced training sessions provided opportunities for additional study, overlearning, distributed practice, and opportunities for retrieval in the form of tests. As has been previously stated, research has shown that each of these factors contributes to an increase in information retrieval in normal subjects. The results of 
this study suggest that these factors contribute to an increased accuracy for word retrieval for subjects who are aphasic.

Subject DS, who frequently exhibited word retrieval problems during conversational speech, had the most severe word retrieval problems of any of the subjects during the training sessions, often requiring over a minute to recall an item. He usually reported that he knew the name, but simply could not "get the word out." He often accurately recalled the first letter and/or the number of syllables in the target name. There were two names that he was never able to recall successfully during any of the training trials, which was not the case for the other subjects. For some of the items missed on the postmaintenance probe, he remembered cues, parts of names, or the initial sounds. He reported having words "on the tip of the tongue," but was unable to retrieve them.

Due to his apraxia, subject $\mathrm{EH}$ had a great deal of difficulty pronouncing some of the names and was given time to make numerous attempts to produce them during the training sessions and the postmaintenance probe. Like subject DS, he recalled cues for some items not successfully named in the postmaintenance probe. This was not surprising because aphasic subjects are often able to describe a function or attribute of a word they cannot successfully retrieve. During training, he also reported the "tip of the tongue" phenomenon, but he did not exhibit or report this phenomenon during the postmaintenance probe as did subject DS.

While subject GM performed with high accuracy during the study, it is interesting to note that his overall PICA score and PICA verbal score was the lowest 
of all 3 subjects. The high levels of naming accuracy by this subject are thought to be the result of his extremely strong motivation to master the task. Post-study interviews revealed that GM mentally rehearsed the target stimuli between training sessions to a far greater extent than the other 2 subjects. This subject achieved a high level of accurate naming early in the training. The overlearning of items may have helped maintain his high level of accuracy throughout the training and during the postmaintenance probe.

Another factor that may have contributed to his high level of accuracy so early in the study was that he created some of the most unique and truly personal of the cues. For example, his cue for Carmen was Riese Stevens, who he explained was an opera singer most famous for her performance in this role. In contrast, the cues by the other subjects were Spanish gypsy girl in opera and beautiful gypsy girl in opera. For David Copperfield, the cue used was Freddy Bartholomew who played this role in a movie. For Sparticus, his cue was Kirk Douglas played the gladiator in a movie. These cues may have helped evoke a highly visual image of an actual person playing a role and may have contributed to the higher accuracy of this subject. Subject GM was also the only subject to create any determinate sentence completion cues. For Dr. Watson, the clue was Elementary, my dear and for Miles Standish, it was speak for yourself, which is a line from a poem by Longfellow. In addition, he appeared to have a more solid background in literature and the theater than the other subjects and definitely had the most solid background in music. He reported that before he had his CVA, he had a keen interest in singing and was proud 
of his ability to memorize songs. He felt that his memorization skills may have been a contributing factor to his high level of performance in this study. After only a few training sessions, he accurately named the pictures before the researcher could read the cue, and therefore, did not appear to be cue dependent. The researcher asked him to wait for the cues so that all subjects could receive identical training, and he complied.

For both subjects DS and EH, two maintenance sessions clearly made a difference in accuracy of recall. It is probable that a combination of factors enhanced their performance. More opportunities for additional study, retrieval by testing, and overlearning existed in the two maintenance session condition, and the practice was distributed.

Following the postmaintenance probe, the following factors were defined and discussed with the subjects: (a) retrieval by testing, (b) study trials, (c) overlearning, and d) distributed practice were defined and discussed in an informal session with subjects DS and EH. They were then asked to speculate which of these factors may have contributed to their higher naming accuracy for the stimuli presented in two posttraining maintenance sessions. Subject DS reported that a combination of distributed practice and additional retrieval opportunities contributed to his higher accuracy for items presented in two additional maintenance sessions. Subject EH reported that distributed practice was the major factor contributing to his higher naming accuracy for these same items. 


\section{CHAPTER V}

\section{SUMMARY AND IMPLICATIONS}

\section{Summary}

For many years, treatment for word retrieval deficits has involved the use of various cueing techniques to help trigger retrieval of target words. Research has shown that accuracy for future retrieval of target words is best achieved by training subjects with semantically based cues. Personalized cues that are created by the subjects themselves to help remember a target word have been shown to be the most effective of the semantically based cues. However, even with the use of personalized cues, accuracy for naming tasks has been found to decrease once training is completed. Current research in memory indicates that, for normal subjects, techniques that facilitate future recall of information include testing, additional study, overlearning, and distributed practice.

This research examined the influence of posttraining maintenance sessions on the long term memory of subjects with aphasia. The goal was to compare the effect on naming accuracy for stimuli (a) presented in two additional training sessions (b) presented in one additional session, (c) not presented in any additional sessions. Additional sessions presented opportunities for testing, study, overlearning, and distributed practice for selected stimuli. 
Three adult male subjects with moderate aphasia created their own cues to help remember 30 pictures of famous characters. During training sessions, these cues were presented to trigger name recall. Following the end of the 3-week training period, the 30 pictures were divided into groups of 10 cards called, A, B, and C. There were two additional training sessions for $\mathrm{A}$, one for $\mathrm{B}$, and none for $\mathrm{C}$. A probe following the last session showed that for two of the subjects, the addition of posttraining maintenance sessions acted to enhance naming accuracy, and two sessions resulted in much higher accuracy than one session. This is consistent with research with normal subjects and suggests that short intermittent training sessions can help maintain naming accuracy with subjects with aphasia.

\section{Implications}

This study provides potentially useful implications in word retrieval treatment. With treatment for aphasia being severely limited for many individuals, the results point to the value of maintenance sessions to re-present target words at spaced intervals. These maintenance sessions could be quickly completed during ongoing therapy. As an alternative, programs could be devised that would allow these maintenance to be done at home, allowing for maximum efficient use of often limited treatment sessions with a speech/language pathologist. Home programs could help maintain recall following discharge.

More research is needed to further investigate the best scheduling for posttraining maintenance sessions. It is possible that a wider interval between sessions 
would be just as effective as the 2-week spacing between the two maintenance sessions used in this study. There is also the question of how long the maintenance sessions would have to continue in order for targeted information to remain readily retrievable. It is possible that the spaced intervals between maintenance sessions could lengthen over time while maintaining accuracy. More research is needed to determine the efficacy of a maintenance program over a longer period of time.

While this study was concerned with maintenance of naming over time, it can be speculated that intermittent maintenance sessions could be of value in other areas of adult cognition, speech, and language treatment. 


\section{REFERENCES}

Allen, G. A., Mahler, W. A., \& Estes, W. K. (1969). Effects of recall tests on long-term retention of paired associates. Journal of Verbal Learning and Verbal Behaviors, 463-470.

Beeson, P. M., Bayles, K. A., Rubens, A. B., \& Kaszniak, A. W. (1993). Memory impairment and executive control in individuals with stroke-induced aphasia. Brain Language, 45, 253-275.

Bjork, R. A., \& Bjork, E. L. (1992). A new theory of disuse and an old theory of stimulus fluctuation. In A. F. Healy, S. M. Kosslyn, \& R. M. Shiffrin (Eds.), From learning processes to cognitive processes: Essays in honor of William $K$. Estes: Vol. 2 (pp. 35-67). Hillsdale, NJ: Hoove and London.

Brookshire, R. H. (1992). An introduction to neurogenic communication disorders. St. Louis, MO: Mosby Year Book.

Carrier, M., \& Pashier, H. (1992). The influence of retrieval on retention. Memory and Cognition, 20, 633-642.

Cooper, A. J. Monk, A. (1976). Learning for recall and learning for recognition. In D. Brown (Ed.), Recall and recognition (pp. 131-156). London: John Wiley \& Sons.

Craik, F. I., \& Lockhart, R. S. (1972). Levels of processing: A framework for memory research. Journal of Verbal Learning and Verbal Behavior, 11, 671-684.

Freed, D. B., Marshall, R. C., \& Nippold, M. A. (1995). Comparison of personalized cueing and provided cueing on the facilitation of verbal labeling by aphasic subjects. Journal of Speech and Hearing Research, 3, 1081-1090.

Goodglass, H. (1993). Understanding aphasia. San Diego, CA: Academic Press.

Goodglass, H., \& Kaplan, E. (1983). The Boston diagnostic aphasia examination. Boston: Lea \& Febiger.

Haynes, W. C., Pindzola, R. H., Emerick, L. L. (1992). Diagnosis and evaluation in speech pathology. Englewood Cliffs, NJ: Prentice-Hall. 
Hillis, A. E. (1989). Efficacy and generalization of treatment for aphasic naming errors. Archives of Physical and Medical Rehabilitation, 70, 632-636.

Hogan, R. M., \& Kintsch, W. (1971). Differential effects of study and test trials on long-term recognition and recall. Journal of Verbal Learning and Verbal Behavior, 10, 562-567.

Howard, D., Patterson, K., Franklin, S., Orchard-Lisle, V., \& Morton, J. (1985a). The facilitation of picture naming in aphasia. Cognitive Neuropsychology, 2, 49-80.

Howard, D., Patterson, K., Franklin, S., Orchard-Lisle, V., \& Morton, J. (1985b). The treatment of word retrieval deficits in aphasia. Brain, 108, 817-829.

Kertesz, A. (1982). The western aphasia battery. New York: Grune and Stratton.

Krueger, W. C. (1929). The effect of overlearning on retention. Experimental Psychology, 12, 71-78.

Landauer, T. K., \& Biork, R. A. (1978). Optimum rehearsal patterns and name learning. In M. M. Gruneberg, P. E. Morris, \& R. N. Sykes (Eds.), Practical aspects of memory (pp. 625-632). London: Academic Press.

Le Dorze, G. (1989). Anomia in moderate aphasia: Problems in accessing the lexical representation. Brain and Language, 37, 381-400.

Li, E. C., \& Williams, A. E. (1989). The efficacy of two types of cues in aphasia patients. Aphasiology, 3, 619-626.

Lockhart, R. S., Cralk, F. I., \& Jacoby, L. (1976). Depth of processing, recognition, and recall. In D. Brown (Ed.), Recall and recognition (pp. 75-102). London: John Wiley \& Sons.

Love, R., \& Webb, W. (1977). The efficacy of cueing techniques in Broca's aphasia. Journal of Speech and Hearing Disorders, 42, 170-177.

Marshall, J., Pound, C., White-Thomson, M., \& Pring, T. (1990). The use of picture/word matching tasks to assist word retrieval in aphasic patients. Aphasiology, $4,167-184$.

Marshall, R. C., Freed, D. B., \& Phillips, D. S. (1994). Labeling of novel stimuli by aphasic subjects: Effects of phonologic and self-cueing procedures. In $\mathbf{M}$. L. Lemme (Ed.), Clinical Aphasiology, 22 (pp. 335-343). Austin, TX: PRO-ED. 
Marshall, R. C., Neuburger, S. I., \& Phillips, D. S. (1992). Effects of facilitation and cueing on labelling of "novel" stimuli by aphasic subjects.

Aphasiology, 6, 567-583.

Patterson, K., Purell, C., \& Morton, J. (1983). Facilitation of word retrieval in aphasia. In C. Code and D. J. Mullers (Eds.), Aphasia therapy (pp. 76-87). London: Edward Arnold.

Pease, D. M., \& Goodglass, H. (1978). The effects of cueing on picture naming in aphasia. Contex, 14. 178-189.

Porch, B. E. (1981). Porch index of communicative ability. Palo Alto, CA: Consulting Psychologists Press.

Pring, T., White-Thomson, M., Pound, C., Marshall, J., \& Davis, A. (1990). Picture/word matching tasks and word retrieval: Some follow-up data and second thoughts. Aphasiology, 4, 479-483.

Rochford, G., \& Williams, M. (1962). Studies in the development and breakdown of the use of names. Journal of Neurology, Neurosurgery, and Psychiatry, 25, 222-227.

Schuell, H. (1972). The Minnesota test for differential diagnosis of aphasia. Minneapolis: University of Minnesota Press.

Thompson, C. K., \& Kearns, K. P. (1981). An experimental analysis of acquisition, generalization, and maintenance of naming behavior in a patient with anomia. Clinical Aphasiology, 24, 35-43.

Wiegel-Crump, C. W., \& Koenigskenecht, R. A. (1973). Tapping the lexical store of the adult aphasic. Cortex, 9, 411-418. 


\section{APPENDIX A}

\section{INFORMED CONSENT}




\section{INFORMED CONSENT}

I, agree to take part in this research project on word retrieval. I understand that in order to participate in this study, I will need to pass a vision and hearing screening test.

I understand that the study involves learning to remember the names of famous people and fictional characters when I am shown their pictures. I will be trained to make up my own cues to help me remember these names. After the initial training session lasting approximately 2 hours, I understand that I will meet with Connie Freed for $1 / 2$ hour sessions three times per week for a three-week period. This will be followed by one 15 minute training session per week for three weeks and one 15 minute final testing period the following week. I understand that, because of this study, I may feel some slight frustration if I can't remember the names during the training and testing sessions.

Connie Freed has told me that the purpose of the study is to learn how to help people maintain accuracy for remembering. names.

I may not receive any direct benefit from taking part in this study, but the study may help to increase knowledge that may help others in the future.

Connie Freed has offered to answer any questions I have about the study and what I am expected to do. I understand that the results of this study may be used for publication or for scientific purposes, but all information I give will be kept confidential and that my identity will remain anonymous.

I understand that I do not have to take part in this study, and that I may withdraw from this study at any time without affecting my relationship with the Veterans Administration Medical Center or with Portland State University. I have read and understand the foregoing information.

Signature

Date

If you experience problems that are the result of your participation in this study, please contact the Chair of the Human Subjects Research and Review Committee, Office of Graduate Studies and Research, 105 Neuberger Hall, Portland State University, 725-3923. 
APPENDIX B

INFORMATION FOR CREATION OF PERSONALIZED CUES 


\section{INFORMATION FOR CREATION OF PERSONALIZED CUES}

William Tell was a legendary Swiss leader who fought to free Switzerland from Austrian rule in the 1600s. As punishment for not showing him the proper respect, the Austrian governor forced William Tell to attempt to shoot an apple placed on his son's head using his bow and arrow. Tell was successful and continued the fight for Swiss independence.

Marco Polo was a famous merchant who traveled with his uncle and father to China and the far east in the 13th century. He was gone for so many years that most people assumed he was dead. When he returned, he wrote a book about his travels which most people thought were tall tails. Marco Polo introduced many new ideas and goods to Europeans.

Miles Standish arrived on the Mayflower in 1620. He was a retired professional soldier and became the military leader of the colony of New Plymouth. Standish became the subject of a poem written by Henry Wadsworth Longfellow entitle "The Courtship of Miles Standish."

Aesop was an ancient Greek writer who lived in the 5th century B.C. He wrote many fables which contained a moral such as the Lion and the Mouse.

Copernicus was a Polish mathematician who was the father of modern astronomy. He was the first to establish that the earth and planets rotated around the sun. Magellan was a Portuguese explorer who sailed around the tip of South America and lead the first known European crossing of the Pacific Ocean. He was killed in the Philippines before he could completely sail around the world. 
Vivaldi was an Italian composer and violinist. He is considered a major composer of the Baroque period and is famous for his work entitled "The Four Seasons."

Louis Pasteur was a French chemist in the 19th century. He discovered that diseases are caused by germs. Pasteur found that dangerous microbes can be destroyed by heat, and the pasteurization process for milk is named after him.

Bathsheba was the wife of a Hittite warrior. King David of Israel fell in love with her and plotted successfully to have her husband killed in battle. Bathsheba then married David, and their second son grew up to become the legendary, wise King Solomon.

Sparticus was a gladiator in ancient Rome. He lead a slave revolt that threatened Rome, but was eventually captured and executed.

Pecos Bill is a fictional character of the old West. According to legend, he was raised by coyotes, rode tornadoes, and wrestled mountain lions and grizzly bears for fun.

Lilly Langtry was a famous British beauty who was the first high society woman to become an actress. She was nicknamed the "Jersey Lily" and was famous for being the mistress of King Edward of England.

Florence Nightingale was the founder of modern nursing. She was known as the "Angel of the Battlefield" to the British soldiers in the Crimean War. After returning to England, Florence Nightingale reformed hospital administration and care.

Hannibal, a Carthaginian general, was considered to be one of the most brilliant military leaders of all times. He crossed the Alps In 218 B.C. with large army that included war elephants. His ambition was to invade Rome, but he did not succeed. 
Annie Oakley was a Pennsylvania farm girl who became an accomplished riflewoman. She paid off her family farm as a young girl from the income from the game she shot and sold at market. Annie later married a famous marksman, and together they joined Buffalo Bill's Wild West Show.

Molly Pitcher was a heroine of the American Revolution. During the Battle of Monmouth, she carried water in a pitcher to her husband and the other men earning her the nickname, Molly Pitcher. When her husband collapsed in battle, she took his place loading the cannon.

Carry A. Nation was an American prohibitionist. She was a large woman who became famous because she would singlehandedly enter and demolish saloons with a hatchet.

Nero was one of the least popular emperors of Rome. He was famous for his extravagance and for putting on lavish shows at the coliseum. Nero supposedly played the fiddle while Rome burned.

Dr. Watson was the friend and assistant to the famous fictional detective Sherlock Holmes. Watson was a London physician, and he and Holmes solved many mysteries together.

Ichibod Crane was a character in the story The Legend of Sleepy Hollow. He was a school teacher who was frightened out of town by the Headless Horseman.

Friar Tuck was a religious monk who befriended the legendary Robin Hood. They lived in Sherwood Forest and together helped the poor of England. 
Romeo is a famous fictional romantic character. He fell In love with Juliet, but because their families were enemies, their romance ended tragically with his death and that of Juliet.

Captain Nemo was the captain of the submarine "Nautilus" in the book Twenty Thousand Leagues Under the Sea. He was hungry for power and eventually, he and his submarine were destroyed.

Don Quixote was a fictional Spanish knight. He was a romantic who was famous for jousting with windmills by mistake.

Yankee Doodle was a legendary soldier in the American Revolution. According to the song, he "stuck a feather in his hat and called it macaroni."

Bob Cratchett was the hard working clerk in the story, A Christmas Carol. He was the loving father of Tiny Tim.

Betsy Ross was a seamstress in Philadelphia during the American Revolution. She was asked to sew the first flag for the new nation using 13 stars to represent the different states.

Juliet was the fictional love of Shakespeare's Romeo. She fell in love with Romeo even though it was forbidden. They both died tragically because of their families' conflict.

Nancy Drew is a fictional detective in a series of stories written for young girls. Nancy's father was an attorney who taught her how to look for clues, and Nancy and her teenage friends solved many mysteries. Scrooge is the fictional miser in Dickens' $A$ Christmas Carol. He is visited by the ghosts of Christmas past, present, and future and sees the error of his ways. 
Queen Ester was a beautiful Jewish girl who was married to the king of Babylon. The king's evil advisor, Haman, plotted to have all the Jews killed. Ester pleaded for the lives of her people. The Jews were saved and the wicked Haman was executed.

Venus was originally the ancient Italian goddess of gardens and spring who later the Roman's worshipped as the goddess of beauty and love. The most brilliant planet in the solar system is named after her.

Carmen is the title and main character of a famous opera. Carmen was a beautiful Spanish gypsy girl. Many soldiers fought over her affections.

King Lear was a famous Shakespearean character and play. King Lear was deceived by his two flattering older daughters and rejected the affection of his youngest daughter, Cordelia, who truly loved him. He lost his kingdom, his youngest daughter, and his life because he could not tell the difference between flattery and love.

David Copperfield is the title and main character of a book by Dickens. After an unhappy boyhood spent in boarding school, David marries a sweet, but empty-headed girl. After her death, he eventually remarries happily and becomes a successful writer. 


\section{APPENDIX C}

\section{TERMINOLOGY}




\section{TERMINOLOGY}

The following terms will be used for the purpose of this research:

anomic aphasia - aphasia that is characterized by fluent grammatically correct speech that is marked by word retrieval failures (Brookshire, 1992).

aphasia - an impairment resulting from brain injury that manifests as interference with the comprehension and use of language. Symptoms may include disturbances in receiving and decoding symbolic materials via auditory, visual, and tactile channels, in the central processes of meaning, word selection and message formulation, and in expressing symbolic materials by means of speech, writing, or gesture (Haynes, Pindzola, \& Emerick, 1992).

confrontation naming - task in which subject is asked to name pictures or objects designated by the clinician (Brookshire, 1992).

The following terms describe various cueing techniques used in research involving confrontation naming tasks. Some examples are provided:

\section{Phonologically Based Cues}

initial phoneme - initial consonant or consonant blend is presented orally by examiner (Pease \& Goodglass, 1978). repetition - subject repeats name of target word.

rhyme judgment - subject required to judge whether the target word rhymes with another word (Howard, Patterson, Franklin, Orcharct-Lisle, \& Morton, 1985a). Example - target word is "cat" - examiner asks, "Does cat rhyme with hat?"

\section{Semantically Based Cues}

auditory word-to-picture naming - subject presented with a set of pictures and asked to point to and name a specific one (Howard et al., 1985a).

determinate sentence completion - an open-ended sentence is orally presented for which there is only one possible target word that can complete it (Pease \& Goodglass, 1978). Example - target word is "camel" - examiner asks,"A large four-legged animal with a hump that is used for transportation in the desert is a ?" 
function - action or use normally associated with the target is presented (Pease \& Goodglass, 1978). Example - target word is "hammer" - examiner states, "You use it to pound nails."

indeterminate sentence completion - an open-ended sentence is orally presented for which there is more than one possible target word that can complete It (Marshall, Neuberger, \& Phillips, 1992). Example - target word is "cow". Examiner asks, "A four-legged animal that lives on a farm is a ?"

location/environmental context - context is described in which the target object occurs (Howard et al., 1985a). Example - target word is "shell" - examiner states, "You find is at the beach."

non-rehearsal auditory word-to-picture matching - subject presented with a set of pictures and asked to point a specific one without naming it (Howard et al., 1985a).

semantic judgments : subject answers questions regarding the semantics of the name of a targeted item (Howard et al., 1985b). Example - target word is "roof" examiner asks," Is a roof part of a house?"

superordinate semantic class of target word - name of the class of object to which the target word belongs is provided (Pease \& Goodglass, 1978). Example - target word is "chair" - examiner states, "It's a piece of furniture."

visual word-to-picture naming - subject points to one picture out of a set of pictures on spoken request (Howard et al., 1985b).

word-to-picture naming - subject matches a written word to one picture presented in a set (Howard et al., 1985b).

The following terms describe various tasks used in learning and verbal behavior training:

distributed practice - study trials presented at spaced intervals.

free recall test - subject is asked to name stimuli presented in previous study trial.

overlearning - the study of items successfully retrieved on previous recall tests.

recognition test - subject asked to select a previously studied stimuli out of a group of items.

study trial - subject presented with target stimuli. 